\title{
CLINICAL PROFILE AND OUTCOME OF 100 NEONATES IN PERSPECTIVES OF NEONATAL CARE IN A TERCIARY HOSPITAL
}

\author{
Tamanna Begum¹, Md Rafiqul Islam²
}

\begin{abstract}
Summary:
Neonatal death accounts for about half of all deaths among under five children. This is a retrospective study using hospital data from Jan'09 to Dec'09 to focus neonatal disease profile, case fatality \& hospital stay. Study was done in pediatric Dept. of Shahid Suhrawardy Medical College and Hospital, Dhaka. $81 \%$ neonates were admitted within the first week of life. Low birth weight was (38\%). Among them 52\% was delivered by normal vaginal and 42\%) having history of home delivery. Highest cases were in neonatal septicemia group (40\%), Perinatal asphyxia (22\%) and LEW (18\%) cases. $72 \%$ cases was discharge from hospital within 7 days of admission. Case fatality was $2 \%$ in both the neonatal septicemia \& Perinatal asphyxia group. To achieve the MDG for child survival need to increase coverage of neonatal care intervention for the poorest \& most vulnerable groups key words: Neonatal care, outcome
\end{abstract}

\section{Introduction:}

Globally the neonatal mortality rate (NMR) is 36 per 1000 live births 1 . It is estimated that about 5 million neonates die every year in low income countries ${ }^{1,2}$ Bangladesh, the NMR declined in the early 1990s but remained between 41-42 per 1000 till 1999- 2003 Infection, prematurely, LBW, and birth asphyxia are main causes of neonatal death in these countries ${ }^{1,3}$ Peri natal and neonatal mortality are increasing important public health issue in many developing countries. In, Bangladesh neonatal death account for about half of all deaths among children under 5 years of age ${ }^{2,4}$ The need for improved neonatal care is apparent throughout the developing world, The saving Newborn lives (SNL) initiative developed a newborn health strategy that improved newborn health. Shahid Suhrawardy Medical College Hospital has a rudimentary neonatal word. It activities and care service need to focus.

1. Dr. Tamanna Begum. DCH, MD, Fellowship., Associate Professor. Department of Paediatrics, Shahid Suhrawardy Medical College and Hospital (ShSMC\& H) Dhaka.

2. Dr. Md. Rafiqul Islam. DCH, MPhil (International Health). Assistant Professor. Department of Paediatrics, Shahid Suhrawardy Medical College and Hospital (SHSMC\& H) Dhaka.

Correspondence:

Dr.Tamanna Begum,

Associate Professor, Department of Pediatrics

Shahid Suhrawardy medical College and Hospital,Dhaka

E-mail-dr tamannafo hotmail.com, dr tbegumfayahoo.com.

\section{Objective:}

1. To know the neonatal diseases profile in our hospital.
2. Fatality and duration of hospital stay of our studied neonates

3. Focus the neonatal care exist in our community.

\section{Methods \& Design:}

It is a retrospective study using hospital data.

Place: The study was carried out in the department of Paediatrics in Shahid Suhrawardy Medical College Hospital.

Duration: January 2007 to December 2007.

Out come variable were diseases profile, fatality, duration of hospital stay, focus the neonatal care exist in our community.

\section{Result:}

Total (n-100) neonates who were admitted in our neonatal ward age within 28 days were taken in the study. Out come variables were neonatal disease, duration of hospital stay and their end results death and discharge. The highest admission (81\%) was within the first week of their life. Among them male were (56\%), and female were $(44 \%)$. Weight of the studied neonate were within 2.5-3.5 kg (62\%) and less then $<2.5 \mathrm{~kg}(38 \%)$.

Among these cases (48\%) was delivered by lower uterine caesarian section (LUCS 48\%) and rest by normal vaginal delivery (NVD 52\%) within these group delivered at home (42\%).

In this study disease profile of admitted neonates were Neonatal septicemia (40\%), perinatal asphyxia (22\%), Low birth weight (18\%) neonatal jaundice of $(9 \%)$ and others(ll\%).

Duration of hospital was less than 7 days in (72\%) cases 
Case fatality was neonatal septicemia and perinatal asphyxia group. (Table-1)

\section{Discussion:}

Bangladesh has one of the highest maternal mortality rate in the world and each year it is estimated that 250 000 babies in the prenatal and neonatal die. As many as $93 \%$ of mothers in Bangladesh delivers at home and non medical birth attendants conduct over $80 \%$ of these deliveries ${ }^{1,5}$. This report also correlates with our result. In Lancet neonatal survival series, most of the death occurs in the first week of life $.99 \%$ of neonatal death arise in low and middle income countries where as one per cent of death in rich countries ${ }^{10}$. Two thirds of these deaths are in sub Saharan African and south east Asia, where coverage of skilled attendance at birth is lowest. Key causes of death are pre-term birth, severe infection, low birth weight and asphyxia. Low birth weight, poverty and maternal health are also important factors 4,7

A neonatal care unit was introduced into rural hospital in Bangladesh ${ }^{3,5}$ Emphasis was on simple care to prevent hypothermia, hypoglycemia and infection ${ }^{2,6}$ In this study showed minimal expenditure and appropriate neonatal care saved the lives of many low birth infants ${ }^{7,8}$ Community based kangaroo mother care for immediate postnatal application in rural Bangladesh, where incidence of home delivery, low birth weight, and neonatal and infant mortality is high and neonatal intensive care is unavailable ${ }^{6,8}$ This study reduces the overall neonatal mortality rate by $27.6 \%$, infant mortality rate by $25 \%$ and low birth weight neonatal mortality rate by $30 \%{ }^{3,9,10}$

Millennium development Goal for child survival; cannot be met without achieving substantial global reduction in neonatal mortality.the strategies to improve newborn health, and advocate increased coverage of intervention to reach the poorest and most under served populations ${ }^{8,9,11}$

Table-1 :Hospital duration and outcome of studied neonates $\mathrm{n}-100$.

\begin{tabular}{|c|c|c|c|c|}
\hline \multirow[t]{2}{*}{ Pattern of diseases } & \multicolumn{2}{|c|}{ Hospital duration } & \multirow{2}{*}{\multicolumn{2}{|c|}{\begin{tabular}{|lr|}
\multicolumn{2}{|l|}{ Outcome } \\
Discharge & Death \\
$\mathrm{n} \%$ & $\mathrm{n} \%$
\end{tabular}}} \\
\hline & $\begin{array}{l}<7 \text { days } \\
n \%\end{array}$ & $\begin{array}{l}>7 \text { days } \\
\mathrm{n} \%\end{array}$ & & \\
\hline Neonatal septicaemia (40) & 30 & 10 & 38 & 2 \\
\hline Perinatal Asphyxia (22) & 15 & 7 & 20 & 2 \\
\hline $\begin{array}{l}\text { LBW(Low birth weight) } 1 \\
18]\end{array}$ & 11 & 7 & 18 & 0 \\
\hline Neonatal Jaundice (9) & 7 & 2 & & \\
\hline Others (11) & 9 & 2 & & \\
\hline
\end{tabular}

\section{Conclusion:}

to achives MDG-4. Therefore, to improve newborn survival Tamanna et. al. in Bangladesh, antenatal care, safe delivery and postnatal check-up must be pronounce as a total package of safe maternity and newborn care. Developing strategies and programs is only the first step down the road to improved neoborn health and survival and taking local measure to save delivery practices. Sample size was very small and further study needed.

\section{References:}

1. Dorothy Flamen. Improving perinatal care sen ice in Bangladesh and Nepal. RCM Midwives Journal 2001: 9; 204296.

2. Patricia Daly, Mary Taylor and Anne Tinker. Integrating essential Newborn care into countries polocios and prorramns. population reference Bureau.

3. David Isaaes. Neonatal sepsis the antibiotic crisis. Indian Paediatrics 2006:42:9-13.

4. Hent KP. Introduction of neonatal care in a rural Bangladesh Hospital: an analysis the first year' operation:annals of tropical paediatrics 1985:5:175-80.

5. Nancy L.Sloan Salahuddin Ahmed . Salidra N.Mitra. Nuzhat choudhurv. Mostique chowdhury et al. Commmunity based kangaroo care mother to prevent neonatal and infant mortally.:Paediatrics 2008 ;121:1047-1059.

6. Shimrit yanir salem. Eyal sheiner, Ehud Zmora. Hillel vardi. liana shaham vardi, Mashe Mazor. Risk factors for early neonatal depsis. Archives of gnyeology and Obstetic.2006;274:56-61.

7. Svargnano, Msharland, P kazmbe. c mwansambo. Neonatal sepsis: an international perspective. Archives of disease in childhood fetal and neonatal 2005: 90:220-224.

8. Knippenberg R. Lawn JE. Darmstadt GL. Begkayia G. P ogstad $\mathrm{H}$. Walalign $\mathrm{N}$ et al. Systematic scaling up of neonatal care in countries.2005:Lancet :365: 1087-98.

9. M arlines J. Paul vk.B hautta. Koblmsky M. Saukat A. Walker N. Bt Bahi R. Pogstand H et al.Neonatal survival . a call for action Lancet 20005:365:1189-97.

10. UNICEF Statistic. Integrated Management of Childhood illness IMCI 2001.

11. World Health organization Bangladesh family and community Health IMCL2000. 